Aus der Abteilung Neurogenetik

(Leiter: Prof. K.-A. Nave, PhD)

des Max-Planck-Instituts für experimentelle Medizin

in Göttingen

\title{
Untersuchung der unterschiedlichen Funktionen des \\ Neuregulin-1 im Hinblick auf die Myelinisierung des peripheren und zentralen Nervensystems
}

\author{
INAUGURAL - DISSERTATION \\ zur Erlangung des Doktorgrades
}

\author{
der Medizinischen Fakultät \\ der Georg-August-Universität zu Göttingen \\ vorgelegt von \\ Bastian Gerrit Brinkmann \\ aus \\ Alfeld (Leine) \\ Göttingen 2012
}


DEKAN: PROF. DR. MED. C. FRÖMMEL

I. Berichterstatter: PD. Dr. med. M. W. Sereda

II. Berichterstatter / in: Prof. Dr. med. M. Simons

III. Berichterstatter / in: Prof. Dr. med. M. Oppermann 


\section{Inhaltsverzeichnis}

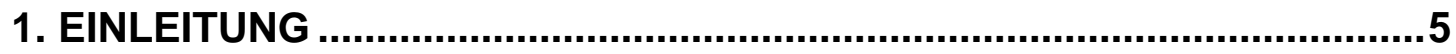

$\begin{array}{lr}\text { 1.1 Das Nervensystem } & 5\end{array}$

$\begin{array}{lr}1.2 \text { Entwicklung von Oligodendrozyten } & 6\end{array}$

$\begin{array}{lr}1.3 \text { Entwicklung von Schwannzellen } & 7\end{array}$

$\begin{array}{lr}\text { 1.4 Die Neureguline und ihre Rezeptoren } & 8\end{array}$

$\begin{array}{lr}1.5 \text { Die ErbB-Rezeptoren } & 9\end{array}$

2. ZIELSETZUNG ..................................................................................11

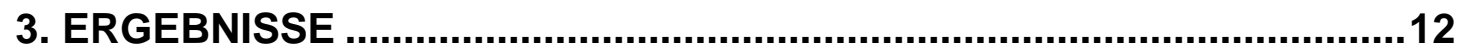

3.1 Die Menge des axonalen Nrg-1-Typs III bestimmt die Myelindicke im peripheren Nervensystem (PNS)
Abbildung 1: Die Nervenleitgeschwindigkeit in Neuregulin-1-Typ-III-transgenen Mäusen ist verlangsamt....................................................................... 13

3.2 Axonales Nrg-1 hat keinen Einfluss auf die Myelinisierung des zentralen Nervensystems (ZNS)

Abbildung 2: Die Myelindicke Neuregulin-1-heterozygoter Mäuse ist im ZNS

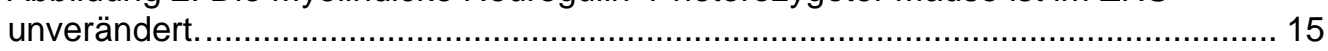

Abbildung 3: Fehlende Myelinisierung des peripheren, aber nicht des zentralen

Nervensystems. .............................................................................. 16

Abbildung 4: Die Myelindicke im Corpus Callosum junger und alter Mäuse ist trotz

Fehlens von Neuregulin-1 unverändert .................................................... 18

3.3 Die Überexpression von Nrg-1 führt zu einer Zunahme der Myelindicke im ZNS 19 Abbildung 5: Überexpression von Nrg-1-Typ I und III führen zu einer erhöhten Myelindicke im ZNS

3.4 Die Überexpression von Nrg-1 führt zu einer verfrühten Myelinisierung, hat aber keinen Einfluss auf die Remyelinisierung

4. DISKUSSION

4.1 Axonales Nrg-1-Typ III reguliert die Myelindicke im PNS 


\section{Abkürzungen}

BACE

bFGF

cDNA

CNP

CNTF

Cre

CSD

E

EGF

ErbB

Grb2

HMSN

IGF-1

MBP

MS

$\mathrm{Nrg}$

NT-3

Oct-6

$P$

P0

PDGF

PNS

S-100

Shc

TACE

TGF $\beta$

Thy-1.2

v-erbB

ZNS $\beta$-site APP-cleaving enzyme

basic fibroblast growth factor

copy DNA (komplementäre DNS)

2',3'-zyklische Nukleotid 3'-Phosphodiesterase

ciliary neurotrophic factor

causes recombination Rekombinase

cortical spreading depression

Embryonaltag

epidermal growth factor

epidermal growth factor receptor

growth factor receptor-bound protein 2

hereditary motor-sensory neuropathies

insulin like growth factor 1

myelin basic protein

Multiple Sklerose

Neuregulin

Neurotrophin-3

POU Illdomain transcription factor

Postnataltag

myelin protein zero

Platelet derived growth factor

peripheres Nervensystem

Calcium bindendes Protein

Src homology domain containing protein

tumor-necrosis factor-converting enzyme

transforming growth factor $\beta$

Thymocyte differentiation antigen 1

erythroblastosis tumor virus

zentrales Nervensystem 


\section{Einleitung}

\subsection{Das Nervensystem}

Das Nervensystem der Vertebraten besteht aus Neuronen und Gliazellen. Es lässt sich in das zentrale Nervensystem (Gehirn und Rückenmark, ZNS) und das periphere Nervensystem (periphere Nerven und Ganglien, PNS) unterteilen. Das zentrale Nervensystem dient neben der Verarbeitung von Informationen peripherer Sinnesorgane unter anderem der Steuerung motorischer Funktionen. Weiterhin ist das ZNS zu höheren Hirnfunktionen wie Gedächtnis und Empfinden von Emotionen fähig. Im PNS sind die Neurone für die Reizaufnahme und -weiterleitung zum ZNS verantwortlich. Dort werden ankommende Informationen prozessiert und verschaltet, um so eine koordinierte Reaktion zu ermöglichen. Die Reizweiterleitung erfolgt hierbei elektrisch entlang des Axons, während die Dendriten der Reizaufnahme dienen. Nervenzellen sind miteinander über Synapsen verbunden, die chemische Transmitter zur Übertragung nutzen (Kandel et al., 2000).

Zu den Gliazellen im ZNS gehören Mikroglia, Astrozyten und Oligodendrozyten. Mikroglia sind residente Immunzellen mesodermalen Ursprungs, die ständig ihre nähere Umgebung auf Pathogene überprüfen und im Fall einer Verletzung zu aktivierten Mikroglia werden. Diese proliferieren, sind höchst beweglich und haben die Fähigkeit zu phagozytieren (Kettenmann und Verkhratsky, 2011). Astrozyten sind sternförmige Zellen mit vielen Fortsätzen, die unter anderem an der Regulation des lokalen $\mathrm{pH}$-Wertes beteiligt sind. Zusätzlich liefern sie den Neuronen Glukose und andere Substrate und nehmen überschüssigen Neurotransmitter an Synapsen auf (Nedergaard et al., 2003). Über sogenannte Endfüße haben Astrozyten engen Kontakt zu Gefäßwänden, was den direkten Austausch von Metaboliten vereinfacht (Kacem et al., 1998). Oligodendrozyten bilden die Myelinscheiden zentraler Axone, indem sie ihre Plasmamembran spiralförmig verlängern. Sie können dabei bis zu 40 Axone unterschiedlichen Durchmessers gleichzeitig umhüllen (Del Rio Hortega, 1928). Die Gliazellen des PNS sind Makrophagen und Schwannzellen. Makrophagen werden nach einem Trauma aus den endoneuralen Blutgefäßen in den Nerv rekrutiert und phagozytieren Myelinreste, was schließlich Regeneration und Remyelinisierung ermöglicht (Gaudet et al., 2011). Schwannzellen kommen in zwei unterschiedlichen Formen vor. Myelinisierende Schwannzellen bilden die 
Myelinscheide peripherer Axone. Im Gegensatz zu Oligodendrozyten gehen sie jedoch eine Verbindung mit nur einem einzelnen Axon ein, und bilden jeweils nur ein Myelinsegment. Nichtmyelinisierende Schwannzellen umschließen eine Gruppe von Axonen kleinen Durchmessers und bilden sogenannte Remakbündel (Friede und Samorajski, 1968).

Die hochorganisierte lipidreiche Myelinscheide dient hauptsächlich der elektrischen Isolierung der Axone. Myelinisierte Fasern haben einen hohen Widerstand und eine niedrige Kapazität, was zu einer Optimierung der Leitgeschwindigkeit führt. Die Myelinscheide ist nicht kontinuierlich, sondern in regelmäßigen Abständen durch die sogenannten Ranvierschen Schnürringe unterbrochen, wo ein Austausch von Metaboliten möglich ist, und eine hohe Dichte spannungsgesteuerter Natrium- und Kaliumkanäle vorliegt. Diese lokale Häufung von lonenkanälen ermöglicht die schnelle saltatorische Reizweiterleitung mit Nervenleitgeschwindigkeiten bis zu 100 $\mathrm{m} / \mathrm{s}$ (Lodisch et al., 2001). Aktuelle Studien der Remyelinisierung legen zudem nahe, dass die Myelinscheide neben der isolierenden Eigenschaft auch dazu beiträgt, Axone zu schützen und zu erhalten (Irvine und Blakemore, 2008).

\subsection{Entwicklung von Oligodendrozyten}

Während der Embryonalentwicklung entstehen Oligodendrozyten und Schwannzellen aus unterschiedlichen Zellpopulationen, dennoch bilden beide Zelltypen Myelin, das morphologisch und biochemisch sehr ähnlich ist. Oligodendrozyten enstehen aus Vorläuferzellen, die aus der Subventrikularzone auswandern. Es bildet sich zunächst eine große Anzahl an Oligodendrozytenvorläuferzellen, von denen einige durch axonalen Kontakt differenzieren, während die meisten durch Apoptose zugrunde gehen. Verschiedene trophische Faktoren spielen bei der Reifung von Oligodendrozyten eine Rolle. Ciliary neurotrophic factor (CNTF), Neurotrophin-3 (NT-3) und Insulin like growth factor 1 (IGF-1) wirken antiapoptotisch auf Oligodendrozyten (Price, 1994). Platelet derived growth factor (PDGF) und basic fibroblast growth factor (bFGF) fördern die Differenzierung von Oligodendrozytenvorläuferzellen (Oligodendrocyteprecursor cells, OPC) zu reifen Oligodendrozyten (Collarini et al., 1991). Des Weiteren beeinflussen Thyroxin, Glukokortikoide, Retinolsäure und TGFß den Differenzierungsprozess von OPCs (McKinnon et al., 1993; Barres et al., 1994). Zusätzlich sind axonaler Kontakt und elektrische Aktivität von entscheidender 
Bedeutung für die Differenzierung von Oligodendrozyten (Chen SJ und DeVries, 1989; Nordlund et al., 1992).

Während der Myelinisierung, die in den ersten Wochen nach der Geburt stattfindet, kontaktieren Oligodendrozyten ein Axon (Miller, 2002; Rowitch, 2004). Faktoren auf der Axonoberfläche entscheiden darüber, ob das Axon myelinisiert wird und wie dick die Myelinscheide sein wird. Eine optimale Leitgeschwindigkeit kann nur erreicht werden, wenn Axondurchmesser und Dicke der Myelinscheide aufeinander abgestimmt sind. Dieses Verhältnis kann durch die Bestimmung des sogenannten Gratio numerisch bestimmt werden. Dieser Quotient aus Axondurchmesser und Gesamtdurchmesser der myelinisierten Faser ist konstant und liegt im ZNS bei etwa 0,8 (Chomiak und $\mathrm{Hu}, 2009$ ).

\subsection{Entwicklung von Schwannzellen}

Schwannzellen enstehen aus der Neuralleiste und durchlaufen mehrere Entwicklungsstadien, bis sie terminal zu myelinisierenden und nichtmyelinisierenden Schwannzellen differenzieren. Zunächst entstehen Schwannzellvorläuferzellen in der Maus am Embryonaltag (E) 12 aus migrierenden Neuralleistenzellen. Sie sind morphologisch bereits eng mit Axonen assoziiert und auf deren Überlebenssignale (,survival factors") angewiesen (Jessen und Mirsky, 2005). Im Unterschied zu Neuralleistenzellen exprimieren Schwannzellvorläuferzellen GAP-43, CD9 und bereits in geringem Maße Myelin-assoziierte Gene wie P0 und PMP22 (Jessen und Mirsky, 2005; Lee et al.,1997; Hagedorn et al., 1999). Zwischen Embryonaltag 13 und 15 entsteht das Bindegewebe des Ischiasnerven und die Vaskularisierung findet statt (Jessen und Mirsky, 2005). Zeitgleich werden die Schwannzellvorläuferzellen zu unreifen Schwannzellen, die über eine autokrine Überlebensschleife verfügen und nicht mehr auf axonale Signale angewiesen sind (Mirsky et al., 2008). Des Weiteren exprimieren unreife Schwanzellen Oct-6 und $\$ 100$ und formen eine Basallamina (Jessen and Mirsky, 2005). Zum Zeitpunkt der Geburt entstehen schließlich zuerst die myelinisierenden Schwannzellen und schließlich die nichtmyeliniserenden Schwannzellen (Mirsky et al., 2008). Differenzierte Schwannzellen zeigen eine bemerkenswerte Plastizität, sodass dieser letzte Differenzierungsschritt nach Nervenverletzungen teilweise umgekehrt werden kann, und Zellen entstehen, die wieder einige Merkmale unreifer Schwannzellen aufweisen und remyelinisieren 
können (Chen ZL et al., 2007; Parkinson et al., 2008; Mirsky et al., 2008). Die Myelinisierung des Ischiasnerven beginnt in der Maus ebenfalls in etwa zum Zeitpunkt der Geburt und führt in myelinisierenden Schwannzellen zu einer stark erhöhten Expression der Gene für die Myelin-assoziierten Proteine und die Lipidbiosynthese (Jessen und Mirsky, 2005). Im PNS werden Axone mit einem Durchmesser von weniger als einem Mikrometer nicht myelinisiert (Voyvodic, 1989). Sie werden in Gruppen zu sogenannten Remak-Bündeln zusammengefasst, und sind mit einer nichtmyelinisierenden Schwannzelle assoziiert. Axone mit einem Durchmesser über einen Mikrometer sind mit einer myelinisierenden Schwannzelle assoziiert und werden myelinisiert. Der G-ratio liegt im PNS bei 0,68 (Donaldson und Hoke, 1905). Wie im ZNS entscheiden auch im PNS axonale Signale darüber, ob eine Faser myelinisert wird oder nicht (Taveggia et al., 2005). Gleichzeitig bestimmen sie die Dicke der Myelinscheide. Wir konnten in diesem Zusammenhang zeigen, dass axonales Neuregulin-1 (Nrg-1) hierbei der entscheidende Faktor ist (Michailov et al., 2004; siehe Ergebnisse).

\subsection{Die Neureguline und ihre Rezeptoren}

Die Neureguline gehören zu einer Gruppe epidermaler Wachstumsfaktoren. Es gibt vier Neuregulin-Gene. Das Neuregulin-1-Gen ist mit 1,5 Megabasen eines der größten Gene im menschlichen Genom. Es kodiert für mehr als 16 verschiedene Isoformen, die durch unterschiedliche Promotoren, alternatives Spleißen und posttranslationale Modifikationen (zum Beispiel proteolytische Spaltung und Glykosylierung) enstehen. Alle Isoformen haben sowohl eine Transmembrandomäne als auch eine EGF (epidermal growth factor)-ähnliche Domäne, die in einer $\alpha$ - und einer $\beta$-Isoform vorliegen kann (Falls, 2003). Davon abhängig besteht eine unterschiedliche Affinität zu den ErbB-Rezeptoren (Burden und Yarden, 1997). Die $\beta$ Isoformen zeigen ein überwiegend neuronales Expressionsmuster, wohingegen die a- Isoformen ein mesenchymales Expressionsmuster aufweisen. Die Nrg-1Isoformen lassen sich in drei Hauptklassen abhängig von ihrem $\mathrm{N}$-Terminus einteilen: Nrg-1-Typ I und II weisen N-terminale Immunglobulin-ähnliche Domänen auf, Typ III hat dagegen eine $\mathrm{N}$-terminale Cystein-reiche Domäne (CRD), die als zweite Transmembrandomäne dient. Nach der proteolytischen Prozessierung durch die Metalloprotease BACE ( $\beta$-site APP-cleaving enzyme) (Hu et al., 2008) oder TACE 
(tumor-necrosis factor-converting enzyme) (Horiuchi et al., 2005) liegen Typ I und II als sezernierte Formen vor, und wirken parakrin, wohingegen Nrg-1-Typ III membranständig bleibt und juxtakrin wirkt (Nave und Salzer, 2006). Es gibt Hinweise, dass es beim Nrg-1-Typ III zu einer weiteren proteolytischen Prozessierung kommt, sodass ein sezerniertes Fragment mit der EGF-Domäne ensteht (Frenzel und Falls, 2001). Neureguline sind nicht nur im Nervensystem exprimiert, sondern spielen auch während der Entwicklung des Herzens eine zentrale Rolle. Genetisch veränderte Mäuse, denen Nrg-1 fehlt, sterben bereits vor der Geburt (Meier und Birchmeier, 1995). Neuregulin-1-Typ III hingegen wird hauptsächlich von Neuronen exprimiert. Es wirkt auf die Proliferation, Differenzierung und Spezialisierung verschiedener Zellen im Nervensystem (Topilko et al., 1996; Jessen und Mirsky, 1997; Jessen und Mirsky, 1998; Lai, 2005).

\subsection{Die ErbB-Rezeptoren}

Die ErbB- Rezeptoren sind membranständige Tyrosinkinasen (ErbB1-4). Ihr Name leitet sich von der Ähnlichkeit mit dem Gen-Produkt des erythroblastosis-Tumor-Virus (v-erbB) ab. Zur Zeit sind elf verschiedene Liganden der Rezeptoren bekannt, unter anderem EGF (epidermal growth factor), Betacellulin, Epiregulin sowie die Neureguline I-IV. Alle vier Rezeptoren haben eine gemeinsame Struktur. Der N Terminus liegt extrazellulär und ist glykosyliert. Dort findet die Bindung der Liganden statt. Er zeichnet sich durch viele Cystein-reiche Domänen aus, die Disulfid-Brücken ausbilden und bei der Dimerisierung eine wichtige Rolle spielen. Nach Bindung eines Liganden kommt es zu einer Konformationsänderung der Rezeptoren, die dann dimerisieren (Burgess et al., 2003). Dabei führt die Ligandenbindung zur Bildung von Homo- oder Heterodimeren, wobei nur ErbB1 und ErbB4 Homodimere ausbilden können (Berger et al., 2004; Citri und Yarden, 2006). Der ErbB2-Rezeptor besitzt keine Ligandenbindungsstelle (Klapper et al., 1999). Er kann allerdings auch ohne gebundenen Liganden dimerisieren und ist der bevorzugte Dimerisierungspartner der anderen ErbB-Rezeptoren (Graus-Porta et al., 1997). Diese Heterodimere besitzen eine hohe Affinität zu Liganden und ermöglichen die Bindung zusätzlicher Liganden (Citri et al., 2003). Nach Dimerisierung werden außerdem verschiedene Bindungsstellen für Adapterproteine wie z.B. Shc oder Grb2, Src Kinasen, Phosphatidylinositol-3-Kinase und Tyrosin-Phosphatasen (SHP1, SHP2) frei (Olayioye et al., 2000). Davon und vom Liganden abhängig werden verschiedene 
Signalwege aktiviert, wie die AKT oder die ERK Signalkaskaden (Olayioye et al., 2000; Carpenter 2003; Citri et al., 2003). Der ErbB3-Rezeptor kann zwar Liganden binden, besitzt aber eine nicht funktionelle Tyrosin-Kinase. Obwohl beide Rezeptoren alleine inaktiv sind, bilden sie in vivo das potenteste Dimer. Dieses spielt bei der Proliferation, Differenzierung und Myelinisierung von Schwannzellen eine entscheidende Rolle (Citri et al., 2003; Nave and Salzer, 2006; Birchmeier, 2009). 


\section{Zielsetzung}

Myelin ermöglicht im Nervensystem der Wirbeltiere eine schnelle saltatorische Impulsweiterleitung und hat somit die Evolution des komplexen menschlichen Gehirns ermöglicht. Der Myelinisierungsprozess wird unter anderem durch Netzwerke verschiedener Faktoren wie Neureguline, Laminine und Integrine reguliert. Die Aufgaben der einzelnen Komponenten sind hierbei oft noch unbekannt. Für die Familie der Neureguline sind bereits verschiedenste Funktionen in der Schwannzellentwicklung (PNS) und in der Migration von Neuronen und Entwicklung von Synapsen (ZNS) bekannt. Im Rahmen dieser Doktorarbeit sollte speziell die Funktion von Neuregulin-1 für die Myelinisierung des ZNS und im Vergleich zum PNS untersucht werden. Hierzu wurden verschiedene genetisch veränderte Mauslinien histologisch, elektronenmikroskopisch und elektrophysiologisch analysiert. Dabei wurde sowohl die Inaktivierung als auch die Überexpression verschiedener Isoformen von Nrg-1 betrachtet. 


\section{Ergebnisse}

3.1 Die Menge des axonalen Nrg-1-Typs III bestimmt die Myelindicke im peripheren Nervensystem (PNS)

Zunächst wurden genetisch veränderte Mäuse untersucht, die nur ein Allel des Gens für Nrg-1 tragen. Diese zeigten im Ischiasnerv dünneres Myelin im Vergleich zu wildtypischen Mäusen (Hypomyelinisierung). Dieser Effekt war für alle Axonduchmesser gleich, die Anzahl an myelinisierten Fasern blieb jedoch unverändert. Es wurde kein Verlust von Axonen beobachtet. Durch elektrophysiologische Untersuchungen konnte eine signifikant verlangsamte Nervenleitgeschwindigkeit als Folge der Hypomyelinisierung festgestellt werden. Durch die Analyse heterozygoter ErbB2-Mäuse konnte des Weiteren bewiesen werden, dass tatsächlich die Verfügbarkeit von Nrg-1 der limitierende Faktor für die Myelindicke darstellt, und nicht die Anzahl der Rezeptoren auf der Schwannzelloberfläche. Die untersuchten ErbB2-Mutanten zeigten keine Veränderung der Myelindicke. Tiere, die nicht nur heterozygot für Nrg-1 waren, sondern auch nur ein Allel für ErbB2 und ErbB3 trugen, zeigten keine stärkere Hypomyelinisierung, wodurch ein zusätzlicher Effekt der beiden Rezeptoren ausgeschlossen werden konnte (Michailov et al., 2004).

Neben den Folgen einer verminderten Menge an Nrg-1 wurde im Rahmen dieser Arbeit auch die Überexpression des entsprechenden Genes in transgenen Mäusen untersucht. Hierzu wurden transgene Mäuse generiert, in denen Nrg-1-Typ I und III unter Kontrolle des Thy-1.2-Promotors spezifisch in Neuronen überexprimiert wurden. Die Überexpression des Nrg-1-Proteins im PNS konnte mit Hilfe von Western Blots in Proteinextrakten des Ischiasnervens bestätigt werden. Durch morphologische Untersuchung der Ischiasnerven transgener Tiere wurde das G-ratio bestimmt, der Quotient aus dem Axondurchmesser und dem Gesamtdurchmesser (Axon und Myelin) gebildet. Dabei zeigte sich eine signifikante Zunahme der Myelindicke in transgenen Tieren, welche die Typ-III-Isoform des Nrg-1 überexprimieren. Die Überexpression der Nrg-1-Typ-I-Isoform hatte dagegen keinen Einfluss auf die Myelindicke. Ein verringerter Axondurchmesser konnte im Falle der Überexpression von Nrg-1-Typ III als Ursache des niedrigeren G-ratios 
ausgeschlossen werden; die Axondurchmesser transgener Tiere waren gegenüber den wildtypischen Kontrollen unverändert.

Man könnte annehmen, dass dickeres Myelin zu einer Beschleunigung der Leitgeschwindigkeit führt. In der elektrophysiologischen Untersuchung der Nrg-1-Typ III überexprimierenden Mäuse ließ sich allerdings eine verlangsamte Nervenleitgeschwindigkeit messen. Wahrscheinlich ist bei einem G-ratio von 0,68 das optimale Verhältnis von Axondurchmesser und Myelindicke erreicht, und ein künstlicher Zuwachs der isolierenden Hülle führt somit zu keiner verbesserten elektrischen Leitung (Abb. 1).

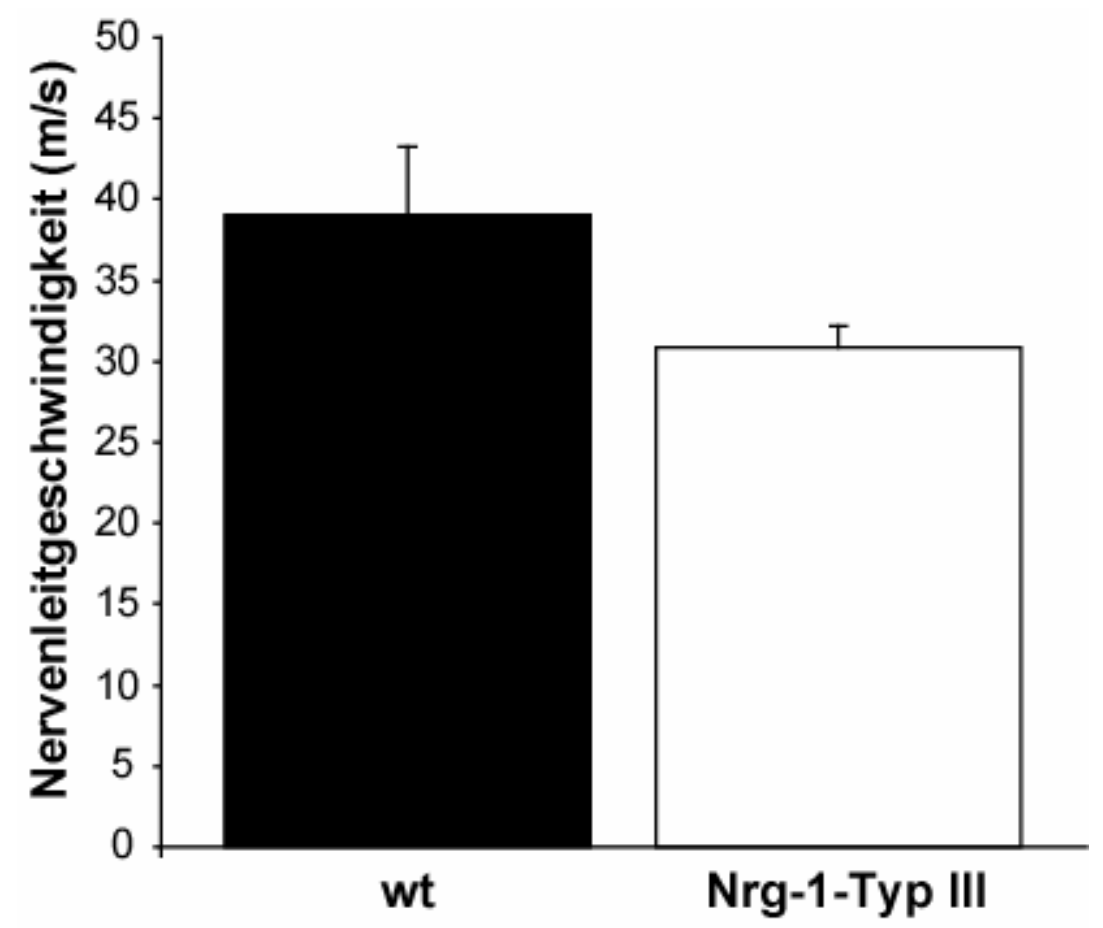

Abbildung 1: Die Nervenleitgeschwindigkeit in Neuregulin-1-Typ-III-transgenen Mäusen ist verlangsamt. Die Muskelsummenaktionspotentiale der intrinsischen Fußmuskulatur wurden nach Reizung des Ischiasnerven am Foramen intrapiriforme und oberhalb des Knöchels gemessen. Aus der Strecke und dem Laufzeitunterschied wurde die Nervenleitgeschwindigkeit errechnet. Diese ist in den Nrg-1-Typ-III-transgenen Mäusen signifikant $(p<0,05)$ niedriger als in den wildtypischen Kontrollen.

Die Schlüsselrolle der Nrg-1-Typ-III-Isoform während der Myelinisierung des PNS konnte weiterhin durch Analyse von Mäusen bestätigt werden, die jeweils nur ein 
Allel der Typ-I- oder der Typ-III-Isoform trugen. Wie im Falle der Überexpression zeigte sich der Effekt auch hier nur für die Tiere, die weniger Nrg-1-Typ-III exprimierten, sie hatten signifikant dünnere Myelinscheiden im Ischiasnerven.

Zusammenfassend lässt sich hieraus schließen, dass die axonal exprimierte Nrg-1Typ-III-Isoform im PNS die Dicke der von Schwannzellen gebildeten Myelinscheide reguliert.

3.2 Axonales Nrg-1 hat keinen Einfluss auf die Myelinisierung des zentralen Nervensystems (ZNS)

Im zweiten Teil der vorliegenden Doktorarbeit wurde die Rolle von Nrg-1 für die Myelinisierung des ZNS untersucht. Hierzu wurden zunächst Nrg-1-heterozygote Mäuse analysiert. Die Myelindicke erschien in allen untersuchten Regionen (Rückenmark, Corpus callosum und optischer Nerv) normal, das G-ratio und die Verteilung der Axondurchmesser waren gegenüber wildtypischen Tieren unverändert (Abb. 2 A und B).

Da Mäuse, die kein funktionales Nrg-1-Gen besitzen, nicht überlebensfähig sind, wurden zur Analyse der Folge einer Inaktivierung von Nrg-1 speziell in Neuronen verschiedene konditionale Mauslinien verwendet. Um zu untersuchen, ob Nrg-1 bereits zu früheren Entwicklungszeitpunkten eine Funktion in Neuronen hat, wurde zunächst die Nestin-Cre-Linie benutzt. Hier findet die Rekombination bereits in neuronalen Vorläuferzellen (E 8,5) statt (Tronche et al., 1999). Diese konditionalen Mutanten starben wie der komplette Nrg-1-,Knockout“ bereits zum Zeitpunkt der Geburt. Bei immunhistochemischer Analyse konnte allerdings eine normale Dichte MBP-positiver Strukturen im Rückenmark festgestellt werden (Abb. 3A). Auf Querschnitten des Rückenmarks inklusive der ventralen Wurzel war der Unterscheid zwischen unmyelinisiertem PNS und normal myelinisiertem ZNS deutlich erkennbar (Abb. 3B). Im Gegensatz zu den konditionalen Mutanten zeigten Kontrolltiere gleichen Alters zu diesem Zeitpunkt keine MBP-positiven myelinisierten Axone im PNS, während im ZNS eine normale Anzahl an MBP-positiven Strukturen vorhanden war (Abb. 3C). 
A

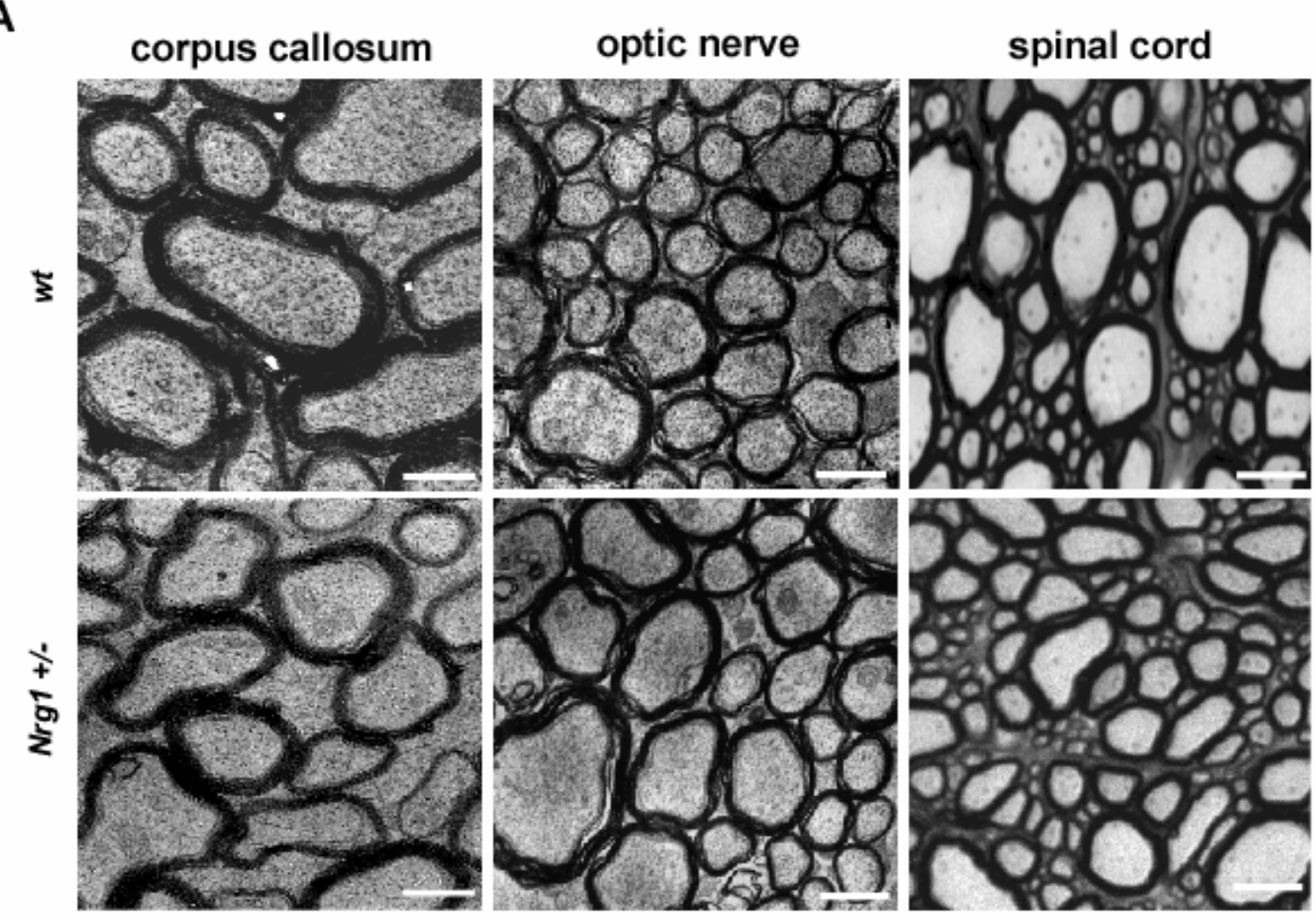

B
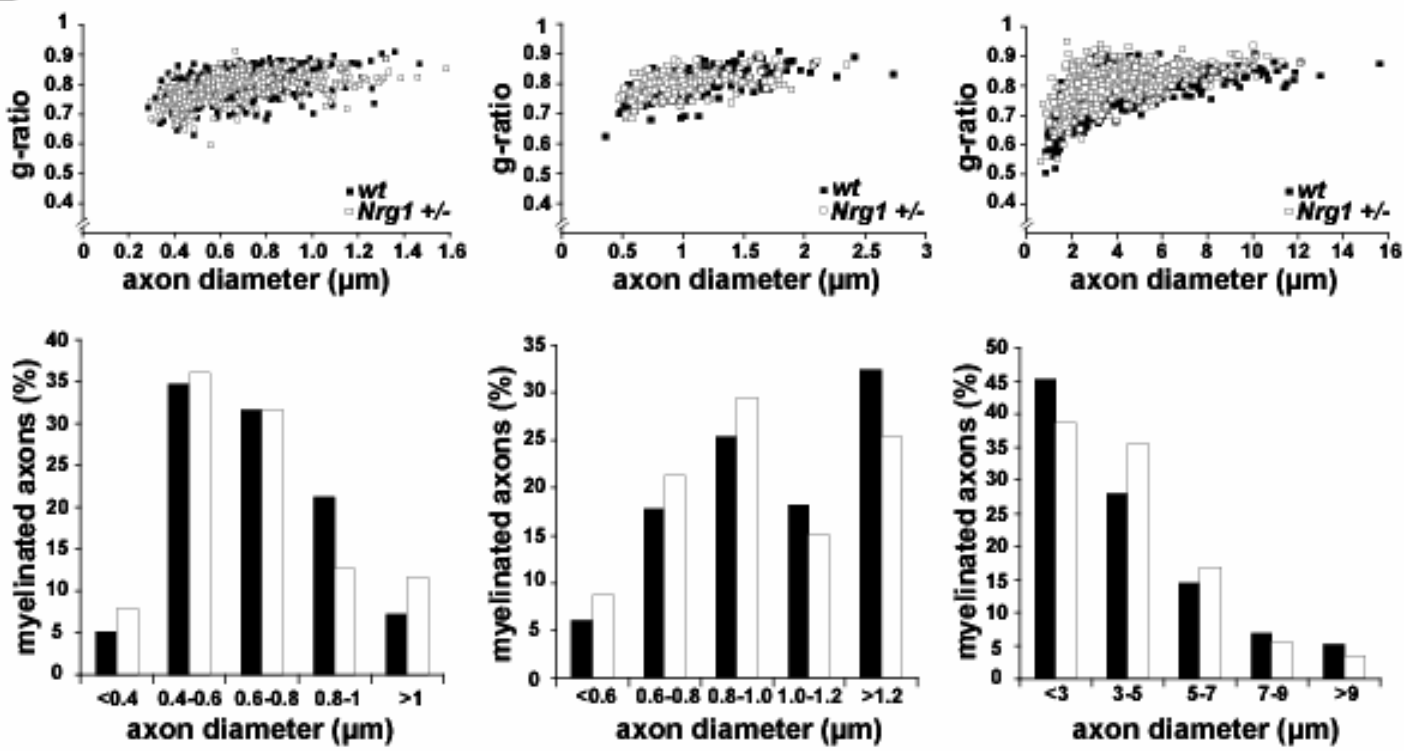

Abbildung 2: Die Myelindicke Neuregulin-1-heterozygoter Mäuse ist im ZNS unverändert. (A) Elektronenmikroskopische Bilder von Querschnitten des Corpus callosums, des optischen Nerven und des Rückenmarks wildtypischer und Nrg-1-heterozygoter Tiere. (B) Darstellung des G-ratios in Abhängigkeit vom Axondurchmesser. Es zeigte sich in den untersuchten Regionen kein Unterschied zwischen wildtypischen und Nrg-1 heterozygoten Mäusen. Die Verteilung der Axone abhängig vom Axondurchmesser war in beiden Genotypen ebenfalls unverändert. Modifiziert aus Brinkmann et al., 2008,suppl. 


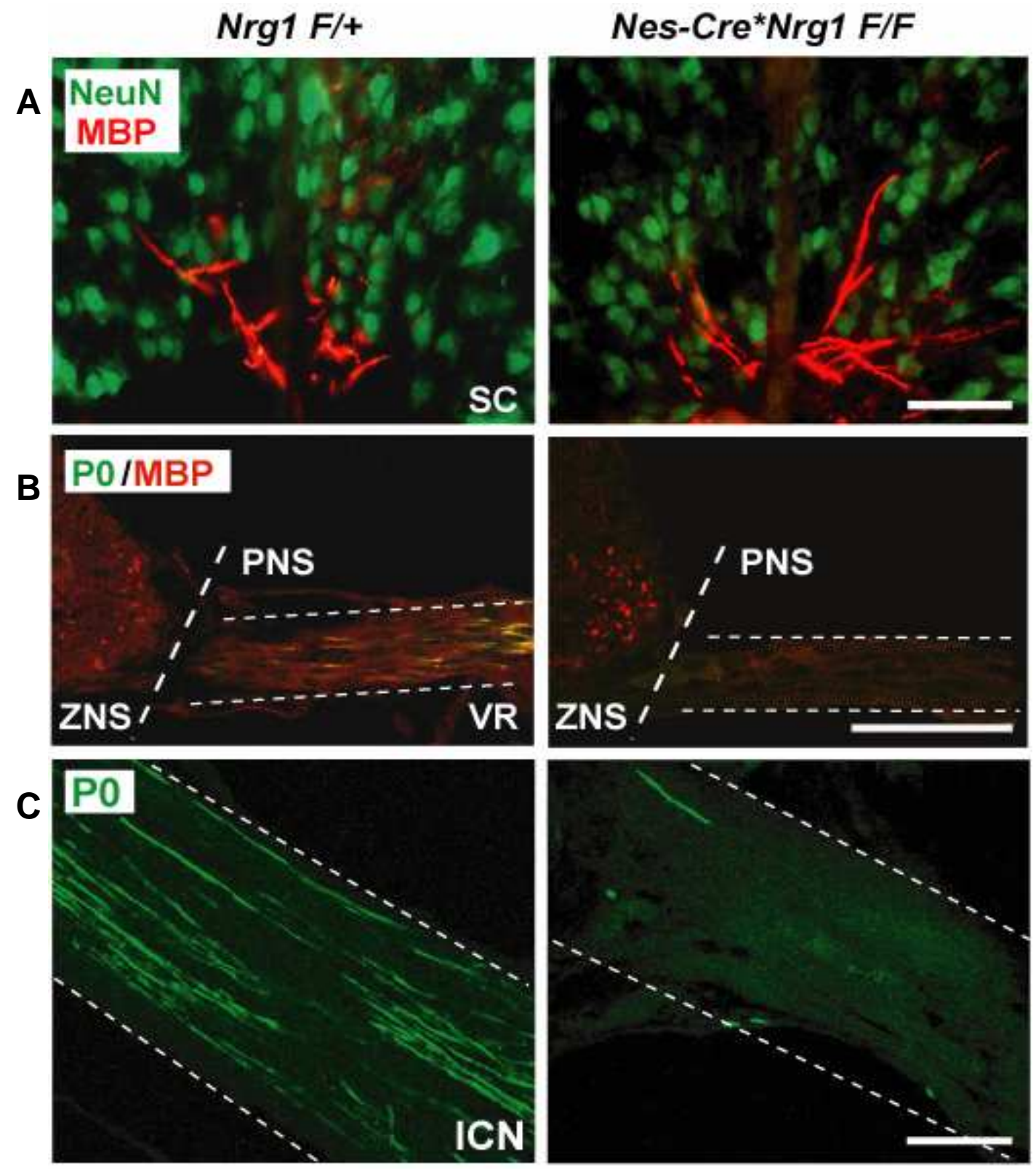

Abbildung 3: Fehlende Myelinisierung des peripheren, aber nicht des zentralen Nervensystems. (A) Normale Dichte MBP-positiver Strukturen im ventralen Rückenmark (SC) an Postnataltag 0. Die immunhistochemische Färbung für NeuN zeigt neuronale Strukturen. (B) Querschnitte des Rückenmarks, auf denen die ventrale Wurzel (VR) zu erkennen ist, zeigen bei Kontrolltieren (Nrg-1 F/+) MBP-positive Strukturen im PNS und ZNS. Im Gegensatz dazu zeigen die Mutanten keine MBP-positiven Strukturen im PNS, jedoch im ZNS. (C) Interkostalnerven mutanter Mäuse zeigen nur ein sehr schwach ausgeprägtes Signal für P0, was auf fehlende Myelinisierung hindeutet. Modifiziert aus Brinkmann et al., 2008,586. 
Des Weiteren wurden Mäuse analysiert, die die Cre-Rekombinase unter Kontrolle des Nex Promotors exprimieren. Hierbei sind alle postmitotischen Neurone nach Embryonaltag (E) 12 rekombiniert. In diesen konditionalen Mutanten ließen sich durch immunhistochemische Untersuchungen ebenfalls keine Unterschiede in der Architektur und Myelinisierung des ZNS feststellen. Auch auf elektronenmikroskopischer Ebene konnte bei 2 und 20 Monate alten Tieren kein Unterschied in der Myelindicke gemessen werden (Abb. 4). 
A

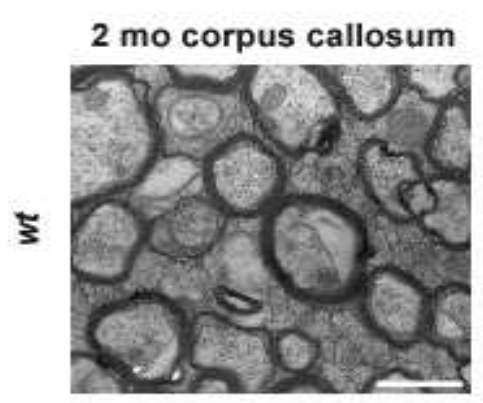

点

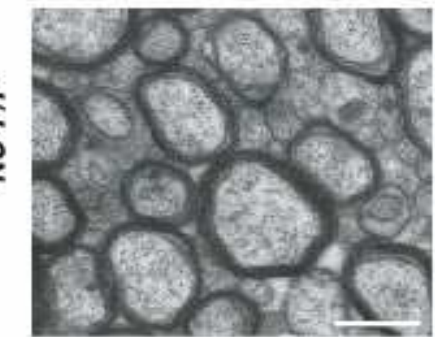

C

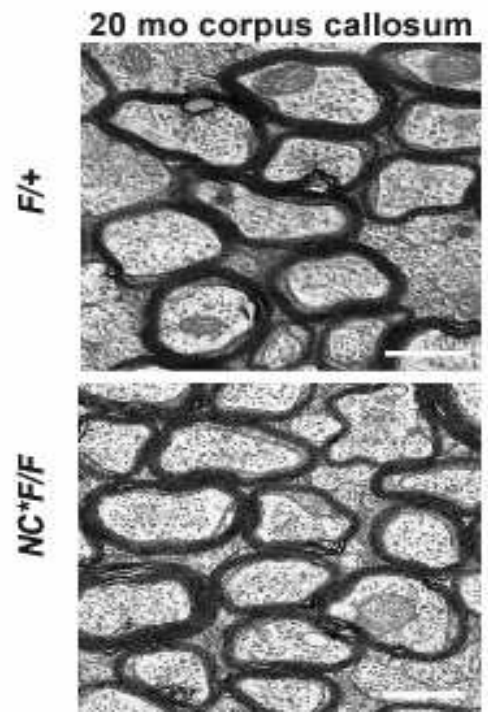

B
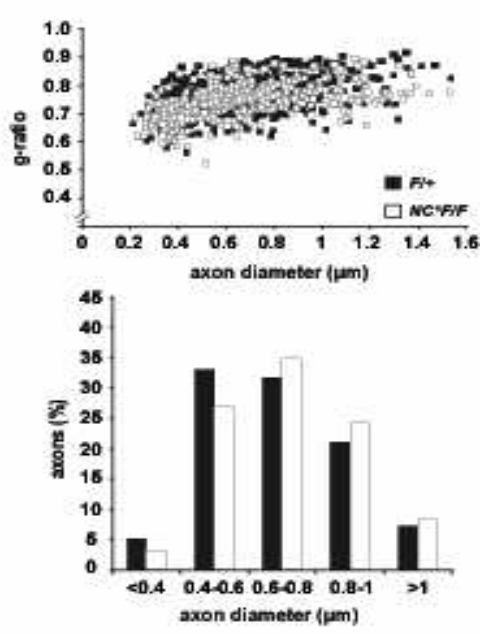

D
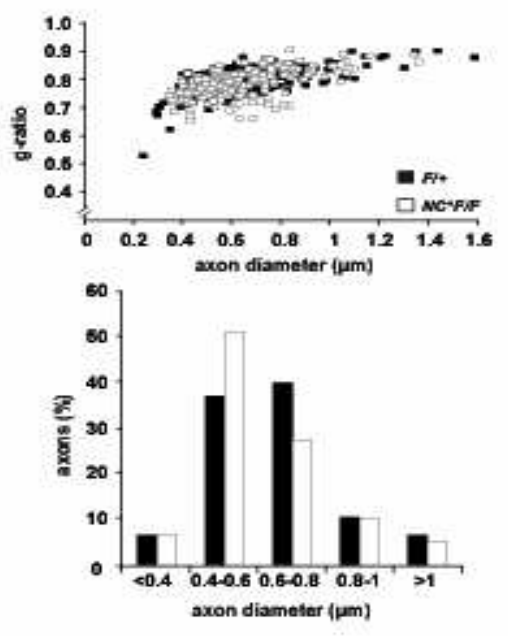

Abbildung 4: Die Myelindicke im Corpus callosum junger und alter Mäuse ist trotz Fehlens von Neuregulin-1 unverändert. (A) Elektronenmikroskopische Bilder von Querschnitten des Corpus callosums bei 2 und 20 Monaten in den Kontrollen und Mutanten. (B) Darstellung des G-ratios in Abhängigkeit vom Axondurchmesser. Es zeigte sich in der untersuchten Region und in den beiden Altersstufen kein Unterschied zwischen Kontrollen und mutanten Mäusen. Modifiziert aus Brinkmann et al., 2008,584. 
Nrg-1 wird im ZNS nicht nur von Neuronen, sondern auch von Astrozyten und Oligodendrozyten exprimiert (Buonanno and Fischbach, 2001). Um auszuschließen, dass von Astrozyten gebildetes Nrg-1 das fehlende neuronale Nrg-1 kompensiert, wurden die ErbB-Rezeptoren 3 und 4 in myelinisierenden Gliazellen mit Hilfe der CNP-Cre-Maus (Lappe-Siefke et al., 2003) inaktiviert. Die Rekombination findet hierbei sowohl in Oligodendrozyten, als auch in Schwannzellen statt. Da ErbB2 keine Ligandenbindungsdomäne besitzt und somit nur im Heterodimer mit ErbB3 wirken kann, sind in dieser konditionalen Maus alle ErbB-Rezeptoren inaktiviert. Wie bereits nach Inaktivierung des Nrg-1-Gens durch Nestin-Cre war auch in diesen Mutanten der morphologische Unterschied zwischen PNS und ZNS deutlich zu erkennen.

Während es im optischen Nerven und Corpus callosum normal myelinisierte Axone gab, waren die Fasern im Ischiasnerv unmyelinisiert. Die Myelindicke im ZNS war im Vergleich zu wildtypischen Mäusen unverändert. Aus diesen Ergebnissen lässt sich schließen, dass eine funktionale Nrg-1/ErbB-Signalkaskade für die Myelinisierung des ZNS im Gegensatz zum PNS nicht benötigt wird. Dies gilt sowohl für neuronale Vorläuferzellen, als auch für postmitotische Neurone. Dennoch sind alle Komponenten im ZNS exprimiert.

\subsection{Die Überexpression von Nrg-1 führt zu einer Zunahme der Myelindicke im ZNS}

Um zu untersuchen, ob eine künstliche Stimulation von Nrg-1 die Myelinisierung verändert, wurden Rückenmark und Corpus callosum transgener Mäuse untersucht, die Nrg-1 überexprimieren (unter Kontrolle des Thy-1.2-Promotors, s.o.). Es zeigte sich eine signifikante Zunahme der Myelindicke in beiden untersuchten Strukturen (Abb. 5 A und B). Erstaunlicherweise traf dies, im Gegensatz zum PNS, auch auf Mäuse zu, die die Typ-I-Isoform überexprimierten (Abb. $5 \mathrm{C}$ ). Weiterhin konnte beobachtet werden, dass im Kortex dieser Tiere nicht nur hypermyelinisierte Axone vorlagen, sondern auch die Gesamtanzahl myelinisierter Fasern signifikant erhöht war.

Letzteres ging allerdings nicht mit einer erhöhten Anzahl an Oligodendrozyten einher, was zu der Hypothese führte, dass die Oligodendrozyten transgener Tiere mehr Myelinsegmente bilden müssen als die der entsprechenden Kontrolltiere. Mit Hilfe dreidimensionaler Rekonstruktionen immunhistochemischer Färbungen konnte 
gezeigt werden, dass die Oligodendrozyten der transgenen Mäuse tatsächlich ein vergrößertes Soma hatten und mit ihren Fortsätzen ein größeres Gebiet abdeckten als die der Kontrolltiere. Somit kann angenommen werden, dass eine einzelne Zelle in diesem Fall mehr Myelinsegmente bildet. Allerdings ist durch die vorliegenden Ergebnisse nicht auszuschließen, dass es gleichzeitig zu einer Zunahme der Internodienlänge gekommen sein könnte.

Um den Einfluss der verstärkten kortikalen Myelinisierung elektrophysiologisch zu untersuchen, wurde in den transgenen Mäusen die kortikale Streudepolarisierung (cortical spreading depression) gemessen. Hierbei werden mit Hilfe einer Kaliumlösung die kortikalen Neurone hyperpolarisiert. Anschließend wird an zwei verschiedenen Punkten erfasst, wie sich eine Welle der Repolarisierung ausbreitet und die Latenz bestimmt. Es ist bekannt, dass es bei chronischer kortikaler Demyelinisierung, z.B. bei Multipler Sklerose, zu einer Latenzverkürzung kommt (Merkler et al., 2009). Analog dazu zeigten die transgenen Mäuse durch die vermehrte kortikale Myelinisierung eine deutlich längere Latenz. 
A

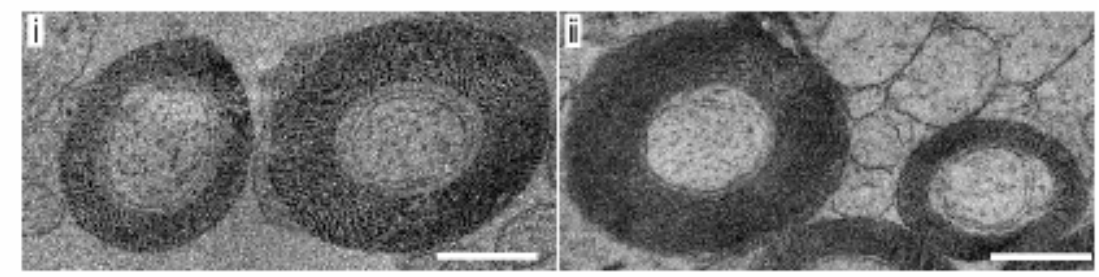

B

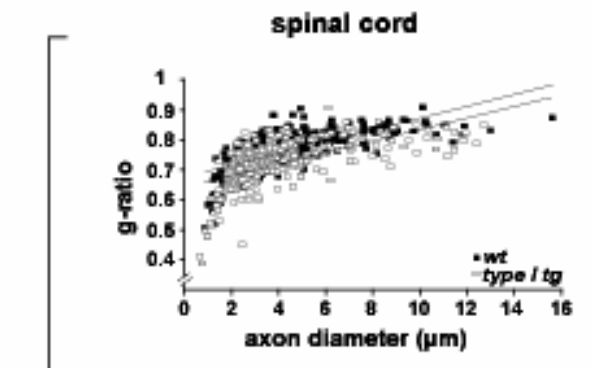

corpus callosum
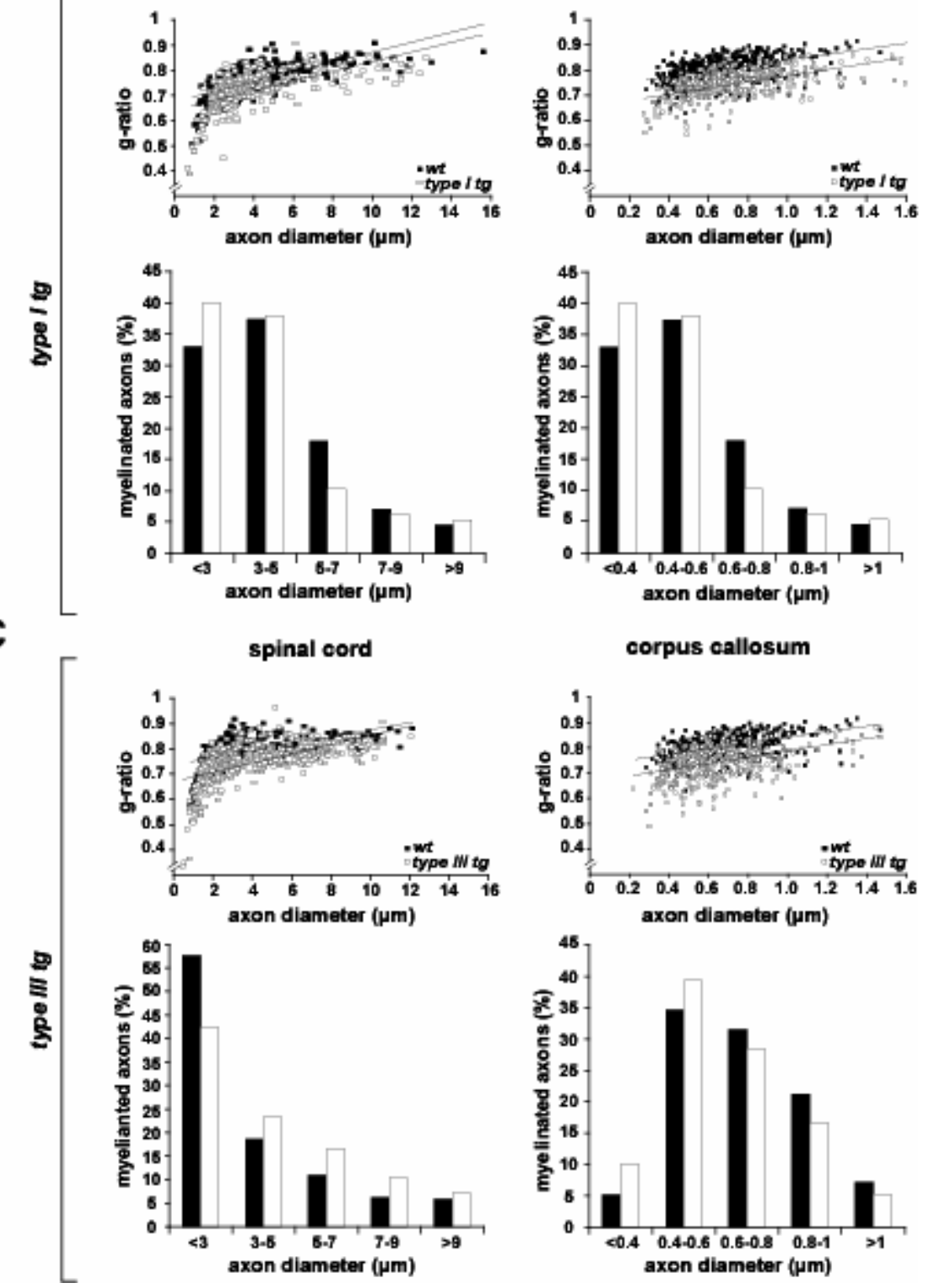

Abbildung 5: Überexpression von Nrg-1-Typ I und III führen zu einer erhöhten Myelindicke im ZNS (A) Elektronenmikroskopische Bilder von Querschnitten des Corpus callosum zeigen sowohl hypermyelinisierte, als auch normal myelinisierte Axone, sehr wahrscheinlich aufgrund mosaischer Expression des Transgen-Konstruktes. Das G-ratio in Abhängigkeit vom Axondurchmesser zeigt Unterschiede zwischen wildtypischen und Nrg-1-Typ-I-(B)- bzw. Typ-III-(C)-transgenen Mäusen im Hinblick auf die Myelindicke. Die Verteilung der Axone abhängig vom Axondurchmesser zeigte zwischen den Genotypen keinen Unterschied. Modifiziert aus Brinkmann et al., 2008,588. 
3.4 Die Überexpression von Nrg-1 führt zu einer verfrühten Myelinisierung, hat aber keinen Einfluss auf die Remyelinisierung

Ein weiterer Effekt der Überexpression von Nrg-1 könnte eine verfrühte Myelinisierung verschiedener Bereiche des ZNS sein, da das Transgen bereits zum Zeitpunkt der Geburt exprimiert wird. In optischen Nerven transgener Mäuse konnte bereits bei P6 eine erhöhte Anzahl myeliniserter Axone festgestellt werden. Die Anzahl der Oligodendrozyten im Vergleich zu Kontrolltieren war dabei unverändert. Dies deutet darauf hin, dass durch Überexpression von Nrg-1 im ZNS die Myelinisierung früher initiiert wurde.

Interessanterweise scheint die Überexpression in adulten Tieren nach Abschluss der Myelinisierung jedoch keinen Effekt mehr zu haben. So konnten wir in Remyeliniserungsexperimenten mit transgenen Mäusen und Kontrolltieren keine Unterschiede in der Anzahl remyelinisierter Axone oder in der Dicke des neu gebildeten Myelins feststellen (Brinkmann et al., 2008; Fig. S7 in Zusammenarbeit mit Ruth M. Stassart). 


\section{Diskussion}

4.1 Axonales Nrg-1-Typ III reguliert die Myelindicke im PNS

Myelinisierung im PNS ist ein fein regulierter Prozess und Veränderungen des Myelins, z.B. aufgrund von demyelinisierenden Erkrankungen, führen zu Neuropathien. Diese gehen mit einer verlangsamten Leitgeschwindigkeit (NLG) einher. Im Rahmen dieser Dissertation konnte axonales Neuregulin-1 als der entscheidende Faktor für die Regulation der Myelindicke im PNS identifiziert werden (Michailov et al., 2004). Dabei ist die Menge an axonal exprimiertem Nrg-1-Typ-III direkt proportional zum Axondurchmesser. Diese Kodierung ermöglicht es der Schwannzelle, die Dicke der Myelinscheide optimal auf die Größe des Axons abzustimmen. Die glialen ErbB-Rezeptoren sind dabei nicht limitierend, sodass tatsächlich die Menge an Nrg-1-Typ III der limitierende Faktor des Axon-Glia Signals ist. Die vorliegenden Ergebnisse passen zu bereits bekannten Funktionen von Nrg-1Typ-I an der neuromuskulären Synapse und der gestörten Myelinisierung in Mäusen, denen der ErbB2-Rezeptor in Schwannzellen fehlt (Garratt et al., 2000). Es konnte gezeigt werden, dass Schwannzellen in vitro Axone von Nrg-1-Typ-III-KnockoutMäusen nicht myelinisieren (Taveggia et al., 2005). Die Wirkung von Nrg-1 wird im PNS durch Wechselwirkung mit weiteren Signalkaskaden während der Entwicklung modifiziert. Eine davon ist die Integrin-Laminin-Signalkaskade. Laminine sind Bestandteile der extrazellulären Matrix im PNS. Integrine stellen die entsprechenden Rezeptoren auf der Schwannzelloberfläche dar. Es konnte gezeigt werden, dass die Interaktion beider Komponenten den Phosphorylierungsgrad der ErbB2- und 3Rezeptoren beeinflusst. In Mäusen, denen das Gen für Laminin-ү1 fehlt, ist die Phosphorylierung von ErbB2 und 3 drastisch reduziert, obwohl die Anzahl an Rezeptoren unverändert ist (Yu et al., 2005). Diese Kontext-abhängige Modulierung des Nrg-1 Signals könnte auch erklären, warum die Überexpression von Nrg-1 in vivo zu einer Hypermyelinisierung führt, während Zugabe von Nrg-1 zu Schwannzellen in vitro eine Demyeliniserung und den Zelltod induziert. In vivo werden gleichzeitg noch andere Signalkaskaden, wie z.B. das Laminin-IntegrinSystem aktiviert im Gegensatz zur in-vitro-Situation. 
Eine wichtige Frage lautet: Wie könnte die Information über den Axondurchmesser die Schwannzelle erreichen?

Während der Differenzierung von Schwannzellen wird der Phosphatidyl-Inositol-3Phosphat(PI-3)-Kinase Signalweg durch ErbB2/3-Rezeptoren aktiviert. Es wäre vorstellbar, dass während der Myelinisierung durch aktive PI3-Kinase phosphorylierte Lipide entstehen, die durch die adaxonale Myelinmembran diffundieren und so das Schwannzellsoma erreichen könnten. Eine weitere Möglichkeit der Signaltransduktion wäre die Diffusion kleiner Moleküle an Schmidt-LantermanInzisuren oder durch Zell-Zell-Verbindungen (gap junctions). Der PI-3-KinaseSignalweg spielt auch für die terminale Differenzierung der Schwannzellen eine Rolle. Die beobachtete Hypomyelinisierung in Nerven von Mäusen, denen ein Allel für Nrg-1-Typ III fehlt, könnte daher eine Folge unvollständiger Schwannzellentwicklung sein.

Ein wichtiges Ziel zukünftiger Studien wäre es, zu verstehen, wie Neurone die Oberflächenexpression von Nrg-1 abhängig von ihrer eigenen Größe regulieren. Auch andere Moleküle, z.B. spannugsgesteuerte Natrium- und Kaliumkanäle, müssen abhängig von Axondurchmesser und -länge exprimiert werden. Erkenntnisse über den entsprechenden Kontrollmechanismus würden weiter zum Verständnis der Myelinisierung beitragen.

\subsection{Axonales Nrg-1 spielt keine Rolle für die Myelinisierung des ZNS}

Die wichtige Rolle von Nrg-1 in der peripheren Myelinisierung ließ vermuten, dass Nrg-1 auch an der Regulation der Myelindicke im ZNS beteiligt sein könnte. Es ist bekannt, dass Oligodendrozyten in vitro und ex vivo durch Nrg-1 stimuliert werden können. Die spontane Remyelinisierung von Läsionen bei Multipler Sklerose könnte Nrg-1-abhängig sein (ffrench-Constant et al., 2004). Für das komplexe Krankheitsbild der Schizophrenie, das auch mit Veränderungen des Myelins einhergehen kann, konnte eine Assoziation mit bestimmten Nrg-1-Haplotypen festgestellt werden (Hall et al., 2006; Davis et al., 2003). Die Kontrolle der 
subkortikalen Myelinisierung durch Nrg-1 könnte daher eine Verbindung zwischen verschiedenen neurologischen Erkrankungen darstellen.

In der vorliegenden Arbeit konnte gezeigt werden, dass die Inaktivierung von $\mathrm{Nrg}-1$ keine Auswirkungen auf die Myelinisierung des ZNS hat (Brinkmann et al., 2008). Durch künstliche etwa 5-fache Überexpression von Nrg-1 in transgenen Mäusen konnte allerdings im ZNS eine Hypermyelinisierung erzielt werden. Hier könnte die Modulation des Systems durch andere Signalkaskaden eine Rolle spielen. So führt die Wechselwirkung von Integrinen der Oligodendrozyten mit Lamininen auf der Axonoberfläche dazu, dass Nrg-1 nicht mehr als Überlebenssignal wirkt, sondern die Differenzierung der Oligodendrozyten erlaubt (Colognato et al., 2002). Interessanterweise führt die Aktivierung des Contactin-Systems zu einer stärkeren Myelinisierung in vitro durch Oligodendrozyten. Im Gegensatz dazu führt eine Blockierung des Integrins zu einer verminderten Myelinisierung in vitro (Laursen et al., 2009).

Die vorliegenden Daten legen nahe, dass die Myelinisierung des ZNS von Nrg-1 „unabhängig“ wurde, während es im evolutionsgeschichtlich älteren PNS weiterhin der entscheidende Faktor für die Myelinisierung ist. Bisher ist nicht bekannt, ob es ein vergleichbares zentrales Signalsystem gibt. Aufgrund der höheren Komplexität des ZNS, sind im ZNS mehrere redundante Regulationsmechanismen für die Steuerung des Myelinisierungsprozesses vorstellbar. Potentielle Kandidaten sind der Wnt/B-catenin Signaltransduktionsweg (Fancy et al., 2009) und die Faktoren Notch (Wang et al., 1998), Jagged und Lingo-1 (Chong und Chan, 2010). Darüber hinaus spielen Transkriptionsfaktoren wie Sox-10, Nkx 2.2, Olig-1 und Myelin gene regulating factor (MRF) eine Rolle. Neuere Studien zeigen, dass sogenannte micro RNAs (miRNAs) die Entwicklung und Myelinisierung von Oligodendrozyten ebenfalls beeinflussen können (Emery et al., 2009). Interessanterweise führt jedoch die Inaktivierung des Neuregulin-1 durch die Überexpression eines dominant- negativen ErbB4-Rezeptors zu einer verstärkten Apoptose von Oligodendrozyten. Weiterhin kommt es in diesen Tieren zu einer veränderten Oligodendrozytenmorphologie, sowie zu einer Hypomyelinisierung (Fernandez et al., 2000; Roy et al., 2007). Diese Diskrepanz zu den hier erhobenen Daten könnte durch eine Störung des Zusammenspiels verschiedener ErbB-Rezeptorkombinationen durch einen einzelnen dominant-negativen Rezeptor zu erklären sein. Weiterhin haben ErbB-Rezeptoren 
verschiedene Affinitäten zu unterschiedlichen Neuregulin-Isoformen, sodass es durch fehlende Interaktion zu einem relativen Verlust des Effektes einer NeuregulinIsoform kommen kann.

Bei verschiedenen Erkrankungen des ZNS kommt es zu einer Zerstörung der Myelinscheide. So wird bei multipler Sklerose (MS) das Myelin im ZNS vermutlich auf Grund von Autoimmunphänomenen abgebaut (Gandhi et al., 2010). Im Nervensystem können Mutationen der Myelinproteine zu einer Dysmyelinisierung und Demyelinisierung führen (Niemann et al., 2006). Im Gegensatz dazu zeigen die hier untersuchten Mutanten mit verringertem Nrg-1-Level im PNS eine Hypomyelinisierung mit unveränderter Zusammensetzung des Myelins. In den Neuregulin-1-heterozygoten Mäusen kommt es im PNS aufgrund der Hypomyelinisierung zu einer verlangsamten Nervenleitgeschwindigkeit, ähnlich wie bei der hereditären motorisch-sensorischen Neuropathie (HMSN) Typ 1. Während die Demyelinisierung bei HMSN-Patienten jedoch progressiv verläuft und zu einer Verschlechterung der Leitgeschwindigkeit führt, zeigen Nrg-1-heterozygote Mäuse eine „definierte“ Hypomyelinisierung. Innen fehlt durch die halbierte Menge an axonalem Nrg-1 eine ganz bestimmte Menge an Myelin. Dies zeigt sich in einem konstanten G-ratio.

Die cortical spreading depression (CSD) ist ein elektrophysiologisches Phänomen und ermöglicht die Messung der kortikalen Repolarisation nach erfolgter Hyperpolarisation und dadurch die Bestimmung der Repolarisationsgeschwindigkeit. Aufgrund der Demyelinisierung bei multipler Sklerose kommt es zu Veränderungen der CSD ebenso bei der Migräne (Merkler et al., 2009).

Auch aufgrund der Überexpression von Nrg-1 kommt es im ZNS zu Veränderungen der CSD. Dies könnte auf eine erhöhte Anzahl myelinisierter Axone oder eine stärkere Myelinisierung einzelner Fasern hindeuten. Das Neuregulin-Signalsystem wirkt sich aber nicht nur auf den Myelinisierungsprozess aus, sondern spielt bekannterweise auch eine Rolle bei der synaptischen Übertragung (Zhong et al., 2008; Fazzari et al., 2010). Veränderte Wechselwirkung verschiedener Signale an der Synapse könnten also eine weitere Erklärung für die beobachteten Veränderungen sein. Dagegen spricht allerdings, dass die CSD bei einer Demyelinisierung genau entgegengesetzt verändert ist. 


\section{Literaturverzeichnis}

Banati RB, Graeber MB (1994): Surveillance, intervention and cytotoxicity: is there a protective role of microglia? Dev Neurosci 16(3-4), 114-27.

Barres BA, Lazar MA, Raff MC (1994): A novel role for thyroid hormone, glucocorticoids and retinoic acid in timing oligodendrocyte development. Development $\underline{120(5)}, 1097-108$.

Berger MB, Mendrola JM, Lemmon MA (2004): ErbB3/HER3 does not homodimerize upon neuregulin binding at the cell surface. FEBS Lett $\underline{569(1-3)}$, 332-6.

Birchmeier C (2009). ErbB receptors and the development of the nervous system. Exp Cell Res 315(4), 611-8.

Brinkmann BG, Agarwal A, Sereda MW, Garratt AN, Müller T, Wende H, Stassart RM, Nawaz S, Humml C, Velanac V, Radyushkin K, Goebbels S, Fischer TM, Franklin RJ, Lai C, Ehrenreich H, Birchmeier C, Schwab MH and Nave KA (2008): Neuregulin-1/ErbB signaling serves distinct functions in myelination of the peripheral and central nervous system. Neuron $\underline{59}, 581-95$.

Buonanno A, Fischbach G (2001): Neuregulin and ErbB receptor signaling pathways in the nervous system. Curr Opin Neurobiol 11(3), 287-96

Burden S, Yarden Y (1997): Neuregulins and their receptors: a versatile signaling module in organogenesis and oncogenesis. Neuron 18(6), 847-55.

Burgess AW, Cho HS, Eigenbrot C, Ferguson KM, Garrett TP, Leahy DJ, Lemmon MA, Sliwkowski MX, Ward CW, Yokoyama S (2003): An open-and-shut case? Recent insights into the activation of EGF/ErbB receptors. Mol Cell 12(3), 541-52.

Carpenter G (2003): ErbB-4: mechanism of action and biology. Exp Cell Res 284(1), 66-77.

Chen SJ, DeVries GH (1989): Mitogenic effect of axolemma-enriched fraction on cultured oligodendrocytes. J Neurochem $\underline{52(1)}$, 325-7. 
Chen ZL, Yu WM, Strickland S (2007): Peripheral regeneration. Annu Rev Neurosci 30, 20933.

Chomiak T, Hu B (2009): What is the optimal value of the g-ratio for myelinated fibers in the rat CNS? A theoretical approach. PLoS One 4(11), e7754.

Chong SY, Chan JR (2010): Tapping into the glial reservoir: cells committed to remaining uncommitted. J CellBiol $\underline{188}, 305-312$

Citri A, Yarden Y (2006): EGF-ERBB signalling: towards the systems level. Nat Rev Mol Cell Biol 7(7), 505-16.

Citri A, Skaria KB, Yarden Y (2003): The deaf and the dumb: the biology of ErbB-2 and ErbB3. Exp Cell Res 284(1), 54-65.

Collarini EJ, Pringle N, Mudhar H, Stevens G, Kuhn R, Monuki ES, Lemke G, Richardson WD (1991): Growth factors and transcription factors in oligodendrocyte development. J Cell Sci Suppl. $\underline{15}, 117-23$.

Colognato H, Baron W, Avellana-Adalid V, Relvas JB, Baron-Van Evercooren A, GeorgesLabouesse E, ffrench-Constant C (2002): CNS integrins switch growth factor signalling to promote target-dependent survival. Nat Cell Biol $\underline{4(11)}$, 833-41.

Davis KL, Stewart DG, Friedman JI, Buchsbaum M, Harvey PD, Hof PR, Buxbaum J, Haroutunian V (2003): White matter changes in schizophrenia: evidence for myelin-related dysfunction. Arch Gen Psychiatry 60(5), 443-56.

Del Rio Hortega P (1928): Tercera aportación al conocimiento morfologica e interpretación funcional de la oligodendroglia. Mem Real Esp Hist Nat 14, 5-122.

Donaldson HH and Hoke GW (1905): On the area of the axis cylinder and medullary sheath as seen in cross sections of the spinal nerves of vertebrates. J Comp Neurol Psychol. $\underline{15}$, 116.

Dugas JC, Cuellar TL, Scholze A, Ason B, Ibrahim A, Emery B, Zamanian JL, Foo LC, McManus MT, Barres BA (2010): Dicer1 and miR-219 Are required for normal oligodendrocyte differentiation and myelination. Neuron $\underline{65(5)}, 597-611$. 
Emery B (2010): Transcriptional and post-transcriptional control of CNS myelination, Curr Opin Neurobiol 20, 1-7.

Emery B, Agalliu D, Cahoy JD, Watkins TA, Dugas JC, Mulinyawe SB, Ibrahim A, Ligon KL, Rowitch DH, Barres BA (2009): Myelin gene regulatory factor is a critical transcriptional regulator required for CNS myelination. Cell 138, 172-185.

Falls, DL (2003): Neuregulins: functions, forms, and signaling strategies. Exp Cell Res 284, 14-30.

Fancy SP, Baranzini SE, Zhao C, Yuk DI, Irvine KA, Kaing S, Sanai N, Franklin RJ, Rowitch $\mathrm{DH}$ (2009): Dysregulation of the Wnt pathway inhibits timely myelination and remyelination in the mammalian CNS. Genes Dev $\underline{23}, 1571-1585$.

Fazzari P, Paternain AV, Valiente M, Pla R, Luján R, Lloyd K, Lerma J, Marín O, Rico B (2010): Control of cortical GABA circuitry development by Nrg1 and ErbB4 signalling. Nature 464(7293), 1376-80.

Fernandez PA, Tang DG, Cheng L, Prochiantz A, Mudge AW, Raff MC (2000): Evidence that axon-derived neuregulin promotes oligodendrocyte survival in the developing rat optic nerve. Neuron 28(1), 81-90.

ffrench-Constant C, Colognato H, Franklin RJ (2004): Neuroscience. The mysteries of myelin unwrapped. Science 304(5671), 688-9.

Forrest AD, Beggs HE, Reichardt LF, Dupree JL, Colello RJ, Fuss B (2009): Focal adhesion kinase (FAK): A regulator of CNS myelination. J Neurosci Res 87(15), 3456-64.

Frenzel KE, Falls DL (2001): Neuregulin-1 proteins in rat brain and transfected cells are localized to lipid rafts. J Neurochem $\underline{77(1)}, 1-12$.

Friede RL, Samorajski T (1968): Myelin formation in the sciatic nerve of the rat. A quantitative electronmicroscopic, histochemical and radioautographic study. J Neuropathol Exp Neurol 27(4), 546-70. 
Gandhi R, Laroni A, Weiner HL (2010): Role of the innate immune system in the pathogenesis of multiple sclerosis. J Neuroimmunol 221(1-2), 7-14.

Garratt AN, Voiculescu O, Topilko P, Charnay P, Birchmeier C (2000): A dual role of ErbB2 in myelination and in expansion of the Schwann cell precursor pool. J. Cell Biol 148, 1035.

Gaudet AD, Popovich PG, Ramer MS (2011): Wallerian degeneration: gaining perspective on inflammatory events after peripheral nerve injury. J Neuroinflammation $\underline{8}, 110$.

Graus-Porta D, Beerli RR, Daly JM, Hynes NE (1997): ErbB-2, the preferred heterodimerization partner of all ErbB receptors, is a mediator of lateral signaling. EMBO $\mathrm{J}$ 16(7), $1647-55$.

Griffin JW, Stoll G, Li CY, Tyor W, Cornblath DR (1990): Macrophage responses in inflammatory demyelinating neuropathies. Ann Neurol 27, Suppl:S64-8.

Hagedorn L, Suter U, Sommer L (1999): P0 and PMP22 mark a multipotent neural crestderived cell type that displays community effects in response to TGF-beta family factors. Development 126(17), 3781-94.

Hall J, Whalley HC, Job DE, Baig BJ, Mclntosh AM, Evans KL, Thomson PA, Porteous DJ, Cunningham-Owens DG, Johnstone EC, Lawrie SM (2006): A neuregulin 1 variant associated with abnormal cortical function and psychotic symptoms. Nat Neurosci $\underline{9(12)}$, 1477-8.

Horiuchi K, Zhou HM, Kelly K, Manova K, Blobel CP (2005): Evaluation of the contributions of ADAMs 9, 12, 15, 17, and 19 to heart development and ectodomain shedding of neuregulins beta1 and beta2. Dev Biol 283(2), 459-71.

Hu X, He W, Diaconu C, Tang X, Kidd GJ, Macklin WB, Trapp BD, Yan R (2008): Genetic deletion of BACE1 in mice affects remyelination of sciatic nerves. FASEB J 22(8), 2970-80.

Irvine KA, Blakemore WF (2008): Remyelination protects axons from demyelinationassociated axon degeneration. Brain 131, 1464-77.

Jessen KR, Mirsky R (1997): Embryonic Schwann cell development: the biology of Schwann cell precursors and early Schwann cells. J Anat 191 (Pt 4), 501-5. 
Jessen KR, Mirsky R (1998): Origin and early development of Schwann cells. Microsc Res Tech 41(5), 393-402.

Jessen KR, Mirsky R (2002): Signals that determine Schwann cell identity. J Anat 200(4):367-76.

Jessen KR, Mirsky R (2005). The origin and development of glial cells in peripheral nerves. Nat Rev Neurosci 6(9), 671-82.

Kacem K, Lacombe P, Seylaz J, Bonvento G (1998): Structural organization of the perivascular astrocyte endfeet and their relationship with the endothelial glucose transporter: a confocal microscopy study. Glia 23 (1), 1-10.

Kandel E, Schwartz J, Jessel T: Principles of neural science. 4. Auflage; Mc Graw Hill New York 2000.

Kettenmann H, Verkhratsky A (2011): Neuroglia - living nerve glue. Fortschr Neurol Psychiatr 79 (10), 588-597.

Klapper LN, Glathe S, Vaisman N, Hynes NE, Andrews GC, Sela M, Yarden Y (1999) : The ErbB-2/HER2 oncoprotein of human carcinomas may function solely as a shared coreceptor for multiple stroma-derived growth factors. Proc Natl Acad Sci U S A 96(9), 4995-5000.

Lai C (2005): Peripheral glia: Schwann cells in motion. Curr Biol 15(9), R332-4.

Lappe-Siefke C, Goebbels S, Gravel M, Nicksch E, Lee J, Braun PE, Griffiths IR, Nave KA (2003): Disruption of Cnp1 uncouples oligodendroglial functions in axonal support and myelination. Nat Genet 33(3), 366-74.

Laursen LS, Chan CW, ffrench-Constant C (2009): An integrin-contactin complex regulates CNS myelination by differential Fyn phosphorylation. J Neurosci 29(29), 9174-85.

Lee M, Brennan A, Blanchard A, Zoidl G, Dong Z, Tabernero A, Zoidl C, Dent MA, Jessen KR, Mirsky R (1997): P0 is constitutively expressed in the rat neural crest and embryonic nerves and is negatively and positively regulated by axons to generate non-myelin-forming and myelin-forming Schwann cells, respectively. Mol Cell Neurosci 8(5), 336-50. 
Lodisch H, Beck A, Zipursky SL, Matsuidara P, Baltimore D, Darnell J: Molekulare Zellbiologie. 4. Auflage; Spektrum Akademischer Verlag Heidelberg, Berlin, Oxford 2001.

McKinnon RD, Piras G, Ida JA Jr, Dubois-Dalcq M (1993): A role for TGF-beta in oligodendrocyte differentiation. J Cell Biol 121(6), 1397-407.

Meier D und Birchmeier C (1995): Multiple essential functions of neuregulin in development. Nature $\underline{378(6555)}, 386-90$.

Merkler D, Klinker F, Jürgens T, Glaser R, Paulus W, Brinkmann BG, Sereda MW, Stadelmann-Nessler C, Guedes RCA, Brück W, Liebetanz D (2009): Propagation of spreading depression inversely correlates with cortical myelin content. Ann Neurol $\underline{66}, 355-$ 365

Michailov GV, Sereda MW, Brinkmann BG, Fischer TM, Haug B, Birchmeier C, Role L, Lai C, Schwab MH, Nave KA (2004): Axonal neuregulin-1 regulates myelin sheath thickness. Science $\underline{\text { 304(5671) }}$, 700-3.

Miller RH (2002): Regulation of oligodendrocyte development in the vertebrate CNS. Prog Neurobiol $\underline{67(6)}, 451-67$.

Mirsky R, Woodhoo A, Parkinson DB, Arthur-Farraj P, Bhaskaran A, Jessen KR (2008): Novel signals controlling embryonic Schwann cell development, myelination and dedifferentiation. J Peripher Nerv Syst. 13(2), 122-35.

Nave KA, Salzer JL (2006): Axonal regulation of myelination by neuregulin 1. Curr Opin Neurobiol 16(5), 492-500.

Nedergaard M, Ransom B, Goldman SA (2003): New roles for astrocytes: redefining the functional architecture of the brain. Trends Neurosci 26 (10), 523-530.

Niemann A, Berger P, Suter U (2006): Pathomechanisms of mutant proteins in CharcotMarie-Tooth disease. Neuromolecular Med. $\underline{8(1-2)}$, 217-42. 
Nordlund M, Hong D, Fei X, Ratner N (1992): Schwann cells and cells in the oligodendrocyte lineage proliferate in response to a 50,000 dalton membrane-associated mitogen present in developing brain. Glia $\underline{5(3)}$, 182-92.

Olayioye MA, Neve RM, Lane HA, Hynes NE (2000): The ErbB signaling network: receptor heterodimerization in development and cancer. EMBO J. 19(13), 3159-67.Price J (1994): Glial cell lineage and development. Curr Opin Neurobiol 4(5), 680-6.

Parkinson DB, Bhaskaran A, Arthur-Farraj P, Noon LA, Woodhoo A, Lloyd AC, Feltri ML, Wrabetz L, Behrens A, Mirsky R, Jessen KR (2008): c-Jun is a negative regulator of myelination. J Cell Biol 181(4),625-37.

Price J (1994): Glial cell lineage and development. Curr Opin Neurobiol 4(5), 680-6.

Rowitch DH (2004): Glial specification in the vertebrate neural tube. Nat Rev Neurosci $\underline{\text { (5), }}$ 409-19.

Roy K, Murtie JC, El-Khodor BF, Edgar N, Sardi SP, Hooks BM, Benoit-Marand M, Chen C, Moore H, O'Donnell P, Brunner D, Corfas G (2007): Loss of erbB signaling in oligodendrocytes alters myelin and dopaminergic function, a potential mechanism for neuropsychiatric disorders. Proc Natl Acad Sci U S A. 104(19), 8131-6.

Tanaka K (2007): Role of glutamate transporters in astrocytes. Brain Nerve 59(7), 677-88.

Taveggia C, Zanazzi G, Petrylak A, Yano H, Rosenbluth J, Einheber S, Xu X, Esper RM, Loeb JA, Shrager P (2005): Neuregulin-1 type III determines the ensheathment fate of axons. Neuron $\underline{47}, 681-694$.

Topilko P, Murphy P, Charnay P (1996): Embryonic Development of Schwann Cells: Multiple Roles for Neuregulins along the Pathway. Mol Cell Neurosci 8(2/3), 71-5.

Tronche F, Kellendonk C, Kretz O, Gass P, Anlag K, Orban P C, Bock R, Klein R, Schutz G (1999): Disruption of the glucocorticoid receptor gene in the nervous system results in reduced anxiety. Nat Genet $\underline{23}, 99-103$.

Voyvodic T (1989): Target size regulates calibre and myelination of sympathetic neurons.

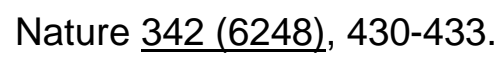


Wang S, Sdrulla AD, diSibio G, Bush G, Nofziger D, Hicks C, Weinmaster G, Barres BA (1998): Notch receptor activation inhibits oligodendrocyte differentiation. Neuron $\underline{21}, 63-75$.

Yu WM, Feltri ML, Wrabetz L, Strickland S, Chen ZL (2005): Schwann cell-specific ablation of laminin gamma1 causes apoptosis and prevents proliferation. J Neurosci $\underline{25}$, 4463-4472.

Zhong C, Du C, Hancock M, Mertz M, Talmage DA, Role LW (2008): Presynaptic type III neuregulin 1 is required for sustained enhancement of hippocampal transmission by nicotine and for axonal targeting of alpha7 nicotinic acetylcholine receptors. J Neurosci 28(37), 91116. 


\section{Originalarbeiten $1,2,3$}

Diese Publikations-Dissertation gründet sich auf folgende Originalarbeiten:

1) Michailov G, Sereda MW, Brinkmann BG, Fischer TM, Haug B, Birchmeier C, Role L, Lai C, Schwab MH, and Nave KA (2004): Axonal Neuregulin-1 regulates Myelin Sheath Thickness. Science 304(5671), 700-3. http://dx.doi.org/10.1126/science.1095862

2) Brinkmann BG, Agarwal A, Sereda MW, Garratt AN, , Müller T, Wende H, Stassart RM, Nawaz S, Humml C, Velanac V, Radyushkin K, Goebbels S, Fischer TM, Franklin RJ, Lai C, Ehrenreich H, Birchmeier C, Schwab MH and Nave KA (2008). Neuregulin-1/ErbB signaling serves distinct functions in myelination of the peripheral and central nervous system. Neuron 59, 581-95. http://dx.doi.org/10.1016/j.neuron.2008.06.028

3) Merkler D, Klinker F, Jürgens $T$, Glaser R, Paulus W, Brinkmann BG, Sereda MW, Stadelmann-Nessler C, Guedes RCA, Brück W, Liebetanz D (2009): Propagation of spreading depression inversely correlates with cortical myelin content. Ann Neurol $\underline{66}, 355-$ 365. http://dx.doi.org/10.1002/ana.21746 


\section{Ganz besonderen Dank an ...}

...Michi für die tolle Zeit im Labor und die ständigen Diskussionen auf dem Balkon ( „laß uns eine dabei rauchen“ Zitat Michi). Weiterhin die Möglichkeit einfach mal was zu machen und unseren Ideen freien Lauf zu lassen egal wie abstrus sie waren.

...Klaus für die Möglichkeit in seinem Labor unter besten Bedingungen zu arbeiten und natürlich die endlosen Diskussionen während des Paper Schreibens.

...Ulli, Carolin, Annette, Eva für die Hilfe bei jeder noch so abstrusen labortechnischen Frage.

...Gabriele, Michaela, Martin, Ulli, Anke für den Grufti-Kaffee, bei dem die wirklich wichtigen Dinge besprochen wurden ( Ankes Erdbeertorte ist die beste).

...Galin, Gerd, Ruth und all den anderen Mitarbeitern und ehemaligen Mitarbeitern der PNS Group, mit denen ich im Laufe der Zeit zusammengearbeitet habe und immer viel Spass hatte.

...Anke dafür, dass sie die beste Benchnachbarin der Welt war.

...dem gesamten Team des Tierhauses, die sich in all den Jahren um meine Mäuse gekümmert haben.

...die gesamten Mitarbeiter der Abteilung Neurogenetik, die mir immer mit Rat und Tat zur Seite standen und meine Zeit dort so besonders gemacht haben.

...Susanne, die mir in allen Lebenslagen immer geholfen hat.

...natürlich meine ganze Familie, die mich immer unterstützt hat. 